\title{
ABUSO SEXUAL, DE CONCIENCIA Y DE PODER: UNA NUEVA DEFINICIÓN
}

Fecha de recepción: 24 de enero de 2020

Fecha de aceptación: 20 de abril de 2020

RESUMEN: El presente trabajo tiene como objetivo mostrar la evolución que ha tenido la definición de abuso sexual. Esta va desde una visión restringida e individual, centrada en la transgresión estrictamente genital, ejercida con fuerza, malinterpretando el fenómeno del abuso de poder en situaciones de vulnerabilidad, facilitando, así, el encubrimiento, la negación institucional y la retraumatización de las víctimas. La evolución va hacia una visión más integral, estructural y ética, que permita a la sociedad, personas e instituciones asumir su verdadera responsabilidad en el reconocimiento y la justicia con las víctimas. Esta es la única manera en que la sociedad y las organizaciones pueden cambiar de una cultura de abuso y encubrimiento a una cultura de atención y confianza lúcida.

PALABRAS CLAVE: abuso sexual infantil; encubrimiento; Iglesia católica; confianza lúcida; vulnerabilidad.

\section{Sexual Abuse, Abuse of Concience and of Power: A New Definition}

ABSTRACT: The present work aims to show the evolution of the definition of sexual abuse. It goes from a restricted and individual view, focused on the strictly genital violation, executed with force, misunderstanding the phenomenon of sexual abuse in vulnerable situations, facilitating the cover-up, the institutional denial and the re-traumatization of the victims. The evolution goes towards a more comprehen-

\footnotetext{
"Pontificia Universidad Católica de Chile: josemurillo@paralaconfianza.com
} 
sive, structural and ethical vision, which allows society, persons and institutions to assume their real responsibility in recognition and justice to victims. This is the way the society and Organizations can change from a culture of abuse and cover-up to a culture of care and lucid trust.

KEY WORDS: child sexual abuse definition; cover-up; Catholic Church; lucid trust; vulnerability.

«C'est l'ambigiuïté insurmountable du Mal qui est son essence» Emmanuel Lévinas (L'Humanisme de l'autre homme)

\section{INTRODUCCIÓN}

Durante la historia de la humanidad, la niñez y adolescencia han sido objeto de las más diversas formas de violencia por parte del mundo adulto ${ }^{1}$. Una de esas formas — que ha sido especialmente silenciada y devastadora, minimizada y normalizada - es la violencia sexual. Más aún en tanto que es cometido mayormente en contextos y por personas que debieran ser de mayor confianza y cuidado, como es el hogar, miembros de la familia, el colegio o la Iglesia ${ }^{2}$. Este crimen ha ido cobrando mayor visibilidad y suscitando mayor indignación social y política junto con la aprobación de la Convención sobre los Derechos del Niño (CDN) en 1989, y el auge de la protección de los derechos de las minorías, a partir de la última década del siglo $\mathrm{XX}^{3}$. Este aumento no ha cesado y ha coincidido, además, con los

${ }^{1}$ Ver, por ejemplo: Lloyd DeMause, ed. The History of Childhood. Nueva York: Rowman \& Littlefield publishers, 1974; Louis A. Jackson. Child sexual abuse in Victorian England. Nueva York: Routledge, 2000; Anne-Claude Ambroise-Rendu. Histoire de la pédophilie XIXe-XXIe siècles. París: Fayard, 2014; Philippe Ariès. L'Enfant et la vie familiale sous l'ancien régime. París: Librairie Plon, 1960; Gil José Sáez Martínez. “Aproximación histórica a los abusos sexuales a menores”. Eguzkilore 29 (2015): 137-170.

2 Según diversas investigaciones estadísticas, sabiendo que es un dato difícil de pesquisar, queda claro que el $90 \%$ de los abusos sexuales son cometidos por personas que conocen a la víctima. El 30\% son cometidos por un miembro de la familia. Los primeros análisis más significativos han sido llevados a cabo por David Finkelhor. Ver, a modo de ejemplo, David Finkelhor, R. Ormrod, H. Turner, y S. L. Hamby. "The Victimization of Children and Youth: A Comprehensive, National Survey". Child Maltreatment 10, n. ${ }^{\circ} 1$ (February 2005): 5-25.

3 Cf., Steven Pinker. Los ángeles que llevamos dentro. El declive de la violencia y sus implicaciones. Barcelona: Paidós, 2011. 
escándalos de abuso sexual infantil cometidos por clérigos y encubiertos por distintas facciones de la jerarquía de la Iglesia, de Diócesis y congregaciones religiosas, marcando la historia reciente de la Iglesia a nivel global ${ }^{4}$.

La protección de los derechos va de la mano de una comprensión de aquello que los daña. En el caso del abuso sexual, durante siglos estuvo centrado en el aspecto genital y la fuerza física cometida en una violación. A lo largo de este estudio buscamos problematizar el concepto de abuso sexual a partir de una visión estructural, buscando establecer una definición que permita comprender de manera más integral y generar estrategias para prevenir y hacer justicia.

Si bien nos concentramos en el abuso sexual cometido en contra de menores de edad, esto es solo porque hasta ahora la asimetría por la diferencia de edad se da por sentada, sin embargo, se busca establecer elementos que permitan comprender la estructura del abuso sexual en tanto abuso de poder.

\section{EVOLUCIÓN DE LA DEFINICIÓN DE ABUSO SEXUAL INFANTIL}

\subsection{Del dualismo mecanicista Del CUeRpo y la Violencia Hacia UNA INTEGRación DEL TRAUMA}

A lo largo de la historia, la relación del ser humano con su propia corporalidad ha tenido manifestaciones diversas. Esta relación ha tenido

${ }^{4}$ Durante los últimos años ha habido una producción importante de documentos que sistematizan y analizan casos de abusos sexuales cometidos en contextos eclesiásticos, aunque reducido a ciertos países. Solo a modo de ejemplo, para el caso de EE. UU., es importante tener en cuenta el llamado John Jay Report. The Nature and Scope of Sexual Abuse of Minors by Catholic Priests and Deacons in the United States 1950-2002. Washington, 2004. Para el caso de Australia se debe consultar: Reporte Final de la Royal Commission de Australia: Royal Commission into Institutional Responses to Child Sexual Abuse, en https://www.childabuseroyalcommission.gov.au/final-report (revisado el 7 de enero de 2020). Para Alemania está el reporte de la Conferencia Episcopal alemana: Sexual abuse of minors by catholic priests, deacons and male members of orders in the domain of the German Bishops' Conference. Resumen en inglés: https:// dbk.de/fileadmin/redaktion/diverse_downloads/dossiers_2018/MHG-Study-eng-Endbericht-Zusammenfassung.pdf (revisado el 7 de enero de 2020), en que se da cuenta de miles de casos de abuso sexual en contextos eclesiásticos ocurridos entre 1946 y 2014. A nivel global el reporte, aunque sin detalle ni trabajo de casos, está el Child Rights International Network CRIN, https://home.crin.org (revisado el 19 de enero de 2020). 
impactos también diferentes en las distintas culturas y ordenamientos jurídicos, donde la sexualidad y la violencia cobran especial relevancia. Así ha sucedido con la comprensión de la violencia sexual en la sociedad occidental desde, a lo menos, el siglo XVI, pasando desde la invisibilidad casi total hasta la consideración del trauma en la violencia durante el siglo XX5 . Solo a partir de la década de 1970 comenzó a cobrar relevancia la violencia simbólica del abuso de poder en general ${ }^{6}$. Esto fue incluyendo la violencia sexual ejercida en los contextos asimétricos, en especial cometida por hombres hacia mujeres y también niños. Si bien durante siglos los ordenamientos jurídicos occidentales han tipificado la violación, hasta bien entrado el siglo XX era raramente perseguida y con escasas encarcelaciones ${ }^{7}$. Eran requeridos altos estándares probatorios, que en algunos casos incluían, además de fuerza ejercida, testigos de la eyaculación ${ }^{8}$.

Una visión mecanicista de la corporalidad ${ }^{9}$ y el mundo, dualista hasta la disociación de la realidad humana, hizo prevalecer la visión de la violencia y el daño desde el punto de vista de la fuerza y dolor físicos ${ }^{10}$, dejando fuera lo no percibido físicamente, como la violencia y manipulación psicológicas como elementos abusivos. Con el desarrollo de la psicología y la fenomenología durante el siglo XX, se ha venido incorporando al concepto de trauma el dolor y la violencia como ejes destructivos de la subjetividad. Esta superación fenomenológica del dualismo en la integración del yo ha permitido elaborar también una comprensión del

${ }^{5}$ Ver, por ejemplo, Sarah Toulalan y Kate Fisher, eds. The Routledge History of Sex and the Body, 1500 to present. Nueva York: Routledge, 2013. Especialmente la parte XII, "Sexual violence and rape", 427 y ss.; y los capítulos 23 y 24, respectivamente: Garthine Walker. "Sexual violence and rape in Europe, 1500-1750", 429-444; Shani D’Cruze. "Sexual violence since 1750", 444-459.

6 Ver especialmente los trabajos de Pierre Bourdieu, por ejemplo, con Jean-Claude Passeron. "Fundamentos de una teoría de la violencia simbólica". En La Reproducción. Elementos para una teoría del sistema de enseñanza, 39-105. Coyoacán (México): Ediciones Distribuciones Fontamara, S.A., 1995 (traducción de la versión francesa. París: Les Éditions de Minuit, 1970).

7 Cf. "Sexual Violence and Rape in Europe", 431.

8 Ibid.

9 Ver el libro de David Le Breton, dedicado a las visiones mecanicistas y disociativas, que socialmente se ha tenido del ser humano respecto de su cuerpo, en Anthropologie du corps et modernité. París: PUF, 1990.

${ }^{10}$ Ver David Le Breton. Anthropologie de la douleur. París: Métailié, 1995. 
trauma de manera más situacional, donde el ambiente en el que la persona se encuentra cumple un rol fundamental ${ }^{11}$. Conceptos jurídico sociales también fueron transformándose por este desarrollo teórico. Así ocurrió, por ejemplo, con la teoría del bien jurídico protegido en derecho penal ${ }^{12}$.

Previo al desarrollo de una teoría de bien jurídico protegido en la subjetividad, como la indemnidad sexual, el daño sufrido por la violencia sexual permanecía en una dimensión distinta del sujeto, como la «naturaleza», el pudor, la moral pública, la decencia o la pureza.

El siglo XIX fue testigo de cambios importantes en las definiciones y delimitaciones de los bienes jurídicos protegidos para los sistemas jurídicos occidentales. En lo que se refiere a los abusos sexuales a menores de edad, los bienes protegidos seguían siendo el pudor (Francia ${ }^{13}$ ), la honestidad (España $\left.{ }^{14}\right)$.

Para el caso de España, por ejemplo:

«El código penal de 1848 dejó de considerar delito la sodomía, pero en la acción penal contra los abusos sexuales a niños se mantenía todavía la mentalidad penal del Antiguo Régimen, y se buscaba proteger más la honestidad de determinadas personas que proteger la sexualidad de los menores» ${ }^{15}$.

Sin embargo, no será sino hasta la publicación y ratificación de la Convención Internacional sobre los Derechos del $\mathrm{Niño}^{16}$, a fines del siglo XX, que el bien jurídico protegido comienza a integrar el interés subjetivo de la víctima a modo de dignidad, o interés superior del niño bajo la forma de indemnidad sexual ${ }^{17}$. La misma indemnidad sexual, sin embargo, debe

11 Ellert Nijenhuis. The Trinity of Trauma: Ignorance, Fragility, and Control. Gotinga: Vandenhoeck \& Ruprecht, 2015. Especialmente los capítulos 7: “The Capricious Historical Understanding of Traumatic Melancholia and Hysteria: Part I. Psychological Considerations", 147-168; y 8: "The Capricious Historical Understanding of Traumatic Melancholia and Hysteria: Part II. Philosophical Considerations", 169-200.

12 Ver Federico Szczaranski. "Sobre la evolución del bien jurídico penal: un intento de saltar más allá de la propia sombra”. Política criminal, n. ${ }^{\circ} 14$ (Diciembre 2012): 378-453.

13 Ambroisse-Rendu. Histoire de la pédophilie XIXe-XXIe siècles. París: Fayard, 2014.

14 G. Sáez. "Aproximación histórica a los abusos sexuales a menores". Eguzkilore 29 (2015): 145.

15 Ibid., 145. Sáez se refiere a los artículos 365-367 del Código Penal de España. Edición Oficial Reformada. Madrid: Imprenta Nacional, 1850.

${ }_{16}$ Ver la Convención en https://www.un.org/es/events/childrenday/pdf/derechos.pdf

17 Ibid., 147. 
ser revisada en cuanto bien jurídico protegido para casos de abuso sexual, donde la devastación subjetiva sobrepasa el ámbito de la sexualidad en su expresión genital. El desarrollo de la teoría del trauma ha constituido una palanca fundamental a la hora de comprender el daño de la violencia subjetiva que significa el abuso sexual, aunque es una tarea en construcción, y aún hay camino por recorrer.

Este camino comenzó durante el siglo XX en ciertas voces aisladas, incluso en el mundo científico. El año 1932 el psicoanalista húngaro Sándor Ferenzci dictó una conferencia en la XII versión del Congreso Internacional de psicoanálisis en Wiesbaden cuyo título original era: "Las pasiones de los adultos y su influencia sobre el desarrollo del carácter y de la sexualidad del niño". Ferenzci ponía en cuestión toda la comprensión y la práctica psicoanalíticas dominantes hasta ese momento respecto del trauma. Ferenzci llamaba a la humildad a los psicoanalistas, a dejar de lado la «hipocresía profesional» y a ser empáticos; a comprender el trauma por el abuso sexual infantil, que era mucho más común de lo que las personas - y los mismos psicoanalistas-creían o admitían. Esta conferencia constituía un contrapunto teórico ante las propuestas de comprensión del abuso sexual como manifestación de una fantasía edípica, más que una realidad.

El abuso sexual fue silenciado durante siglos, y en el siglo XX el mundo científico entraba en conflicto por hacerlo también. Si era cometido en contra de un niño o niña, podía ser considerado una fantasía edípica; y si era cometido en contra de una mujer mayor de edad, sin pruebas de violencia, se presumía consentimiento e histeria. Niños edípicos y mitómanos, mujeres histéricas o seductoras ${ }^{18}$.

La conferencia de Ferenzci fue silenciada por cerca de 50 años hasta ser redescubierta y traducida recién en los años 80 . El propio Ferenzci sufrió el ostracismo, el rechazo y aislamiento de parte de esta comunidad científica, por haberla cuestionado desde la empatía y el pensamiento crítico. Murió un año después ${ }^{19}$.

${ }^{18}$ Ver, en especial, en el libro de Anne-Claude Ambroisse-Rendu. Histoire de la pédophilie. Sobre todo, el capítulo 6: "Mythomannes ou séductrices?", 146ss.

${ }_{19}$ Ver de Jeffrey Moussaieff Masson. The Assault on Truth: Freud's Suppression of the Seduction Theory 2012, especialmente el capítulo 5: "The Strange Case of Ferenczi's last Paper", 239-305 (en la versión impresa). 
Nuevamente no fue sino hasta la década de los 90 que estos paradigmas comenzaron a ser cuestionados estructuralmente. El auge de los derechos de las minorías y el feminismo constituyeron una nueva lucidez en la sociedad occidental respecto de la lucha contra la violencia ${ }^{20}$.

La evolución hacia una comprensión más integral del trauma por violencia sexual, cuando trasciende la fuerza física impuesta por la violación, ha sido lenta. Apunta a la necesidad de una justicia coherente respecto del daño cometido y que sea, a la vez, preventiva.

\subsection{El caso de la Iglesia Católica y La JUSTICIA CANÓNICA RESPECTO DEL ABUSO SEXUAL}

En el caso de la Iglesia católica la evolución también ha sido lenta. La justicia canónica hasta el día de hoy carece de una tipificación suficientemente comprensiva del abuso sexual como para adoptar políticas integrales de prevención, intervención y justicia. El mismo bien jurídico protegido en las definiciones del Código Canónico requiere de una actualización. En efecto, en el Código se castiga la incitación a cometer un pecado en contra del sexto mandamiento ${ }^{21}$, cuando ha sido cometido con violencia, amenazas, públicamente o con un menor de edad ${ }^{22}$. $\mathrm{O}$ cuando ha incitado a un penitente a cometer un pecado contra el sexto mandamiento ${ }^{23}$.

Dejando de lado posibles razones teológicas, a ojos de una víctima, el hecho de que la justicia canónica persiga el pecado en contra del sexto mandamiento sobre su dignidad herida constituye una falta de reconocimiento

20 Steven Pinker.

21 «El sacerdote que, durante la confesión, o con ocasión o pretexto de la misma, solicita al penitente a un pecado contra el sexto mandamiento del Decálogo, debe ser castigado, según la gravedad del delito, con suspensión, prohibiciones o privaciones; y, en los casos más graves, debe ser expulsado del estado clerical». (CIC, canon 1387).

${ }^{22}$ Canon 1395 §2: «El clérigo que cometa de otro modo un delito contra el sexto mandamiento del Decálogo, cuando este delito haya sido cometido con violencia o amenazas, o públicamente o con un menor que no haya cumplido dieciséis años de edad, debe ser castigado con penas justas, sin excluir la expulsión del estado clerical cuando el caso lo requiera» (la cursiva es nuestra).

${ }^{23}$ Canon 1387: «El sacerdote que, durante la confesión, o con ocasión o pretexto de la misma, solicita al penitente a un pecado contra el sexto mandamiento del Decálogo, debe ser castigado, según la gravedad del delito, con suspensión, prohibiciones o privaciones; y, en los casos más graves, debe ser expulsado del estado clerical». 
y, por lo mismo, un nuevo trauma. En efecto, si pensamos con Paul Ricoeur $^{24}$ que la sanción penal tiene un rol también de reconocimiento de víctima de quien ha sufrido la vulneración, en tanto que en este tipo de vulneraciones hay una especial sensación de culpa y vergüenza, entonces la sanción debe conducir a la víctima a significar su trauma y reconocerla como tal, es decir, víctima. De lo contrario, cuando se disocia la causa de la sanción provoca la experiencia de anulación del yo herido. Esta falta de reconocimiento está en la base del rechazo de tantas personas por las reacciones y faltas de reacciones de parte de la Iglesia en tanto institución. El reconocimiento libera a la víctima, reorganiza su realidad y su memoria para una resiginificación sanadora. La profundidad del daño del abuso reside en la ambigüedad. Por el contrario, el reconocimiento del daño en la víctima por y ante un tercero, puede reconstruir la subjetividad herida ${ }^{25}$. La justicia, en todas sus manifestaciones, debe apuntar a romper la ambigüedad del abuso, esencia de su maldad, hacia un reconocimiento regenerativo.

En el año 2014, el Comité de los Derechos del Niño presentó un informe respecto de la manera en que la Iglesia católica había tratado el problema del abuso sexual infantil, sosteniendo que ha prevalecido la intención de proteger su propia reputación más que el interés de los niños que están bajo su responsabilidad.

«Preocupa al Comité que la Santa Sede no haya tenido debidamente en cuenta el interés superior del niño como una consideración primordial en sus procedimientos legislativos, administrativos y judiciales, así como en sus políticas, programas y proyectos relacionados con la infancia y que repercuten en ella. En particular inquieta al Comité que, como lo señalaron varias comisiones de investigación nacionales al examinar las denuncias de abuso sexual de niños, la Santa Sede haya preferido sistemáticamente preservar la reputación de la Iglesia y proteger a los autores de dicho abuso, y no el interés superior del niño ${ }^{26}$.

El comité no cuestiona solo el manejo que, como Iglesia, ha llevado los casos de abuso y encubrimiento, sino también, aunque de manera

${ }^{24}$ En especial en su conferencia sobre justicia o venganza publicada bajo el título “Sanción, rehabilitación, perdón”. En Le Juste. París: Esprit, 1995.

${ }_{25}$ Ver Jessica Benjamin. Beyond Doer and Done To. Recognition Theory, Intersubjectivity and the Third. Nueva York: Routledge, 2018.

${ }_{26}$ Comité internacional sobre los derechos del niño. "Observaciones finales sobre el segundo informe periódico de la Santa Sede”, 2014, n. 29. 
indirecta, el bien que busca proteger, el valor que guía a la Iglesia en estos casos: la dignidad y bienestar de los niños y niñas bajo su protección o su propia reputación. Y de aquí surge, para nosotros, la pregunta por el concepto y definición de abuso sexual que está en la base del bien jurídico protegido que lo sanciona. En efecto, el bien jurídico protegido, que no siempre es explícito en un ordenamiento jurídico penal, es clave para comprender el habitus que estructura a la sociedad que lo establece. Se discute si hay ciertos bienes que, por sus características éticas, psicológicas, políticas, económicas, son «acreedores del estatus de bien jurídico, de forma tal que solo ellos podrán ser legítimamente protegidos por la norma penal $\aleph^{27}$. ¿Es, entonces, el principio de lesividad el que da sentido a la protección de un bien jurídico o es el propio ordenamiento jurídico, desde su lógica interna, que establece sus bienes jurídicos protegidos como una suerte de tautología? ${ }^{28}$. La pregunta nos parece importante porque apunta a la posibilidad de una evolución del derecho penal, independiente del ordenamiento jurídico del que se trate. Sea de un país, una comunidad de países o el Código Canónico.

Más allá de los desaciertos y escándalos que provocó especialmente la jerarquía de la Iglesia, tanto a nivel central como en muchas localidades, y que está latamente desarrollada por diferentes investigaciones históricas $^{29}$, psicológicas ${ }^{30}$, documentales ${ }^{31}$ o películas ${ }^{32}$, se busca profundizar en una posible nueva definición integral de abuso sexual.

27 Federico Szczaranski.

28 Ibid.

${ }^{29}$ Recomendamos la visión de línea de tiempo de Kieran Tapsell. Potiphar's Wife. The Vatican's Secret and Child Sexual Abuse. Adelaide: ATF Press, 2014, cap. 3: "Chronology of Church Response to clergy sexual abuse of children”. Libro E-book. También: Jo Renee Formicola. Clerical Sexual Abuse, How the Crisis Changed US Catholic. Nueva York: Palgrave Macmillan, 2014

${ }^{30}$ Ver Mary Gail Frawley-O'Dea. Predatory Priests, Silenced Victims. The Sexual Abuse Crisis and The Catholic Church. London: The Analytic Press, 2007.

${ }^{31}$ Alex Gibney, dir. Mea Maxima Culpa. El silencio en la casa de Dios. HBI, 2012. Albert Solé, dir. Examen de Conciencia. Netflix, 2019.

32 Tom McCarty, dir. Spotlight. Anonymous Content, Participant Media, First Look Media, Rocklin/Faust, 2015 (Ganadora del Oscar a la mejor película). Trata de los esfuerzos de los periodistas del Boston Globe por develar los abusos y encubrimientos en la Arquidiócesis de Boston. Expone los actos de encubrimiento del cardenal Bernard Law. François Ozon, dir. Grâce à Dieu. Mandarin Films y Scope Pictures, 2019. 
Para actualizar, en todo ordenamiento jurídico, el bien jurídico protegido en el delito de abuso sexual es necesario profundizar en el concepto y definición de abuso sexual en sí. En este sentido, comprender el abuso no solo en tanto acto aislado, sino como un acto dentro de una cultura que lo hace posible, será fundamental.

\subsection{Cultura del abuso}

Durante el año 2018, el papa Francisco publicó dos cartas respecto del abuso sexual que han sido centrales para el presente estudio. El 31 de mayo envió la "Carta al pueblo de Dios que peregrina por Chile", a raíz de los casos de abuso sexual y encubrimiento que golpeaban a la Iglesia en Chile. En esta carta ya se refiere no solo al abuso sexual, sino al encubrimiento y a una cultura que sostiene al uno y al otro.

«El "nunca más" a la cultura del abuso, así como al sistema de encubrimiento que le permite perpetuarse, exige trabajar entre todos para generar una cultura del cuidado que impregne nuestras formas de relacionarnos, de rezar, de pensar, de vivir la autoridad; nuestras costumbres y lenguajes y nuestra relación con el poder y el dinero. Hoy sabemos que la mejor palabra que podamos dar frente al dolor causado es el compromiso para la conversión personal, comunitaria y social que aprenda a escuchar y cuidar especialmente a los más vulnerables. Urge, por tanto, generar espacios donde la cultura del abuso y del encubrimiento no sea el esquema dominante» ${ }^{33}$.

Ya no se abordan como actos aislados, sino como una cultura; y se habla de un "sistema de encubrimiento» que le permite que el abuso tenga lugar, se instale, se silencie, normalice y perpetúe. Se trata de un sistema que se teje dentro de una cultura, que constituye en sí una cultura. Si se cultiva un sistema abusivo se cosecha fácilmente acciones sistemáticas de abuso sexual.

En agosto de ese mismo año, el papa envió otra carta, ya no solo sobre el abuso sexual en sí, sino acerca del abuso de poder y de conciencia. De esta manera, por una parte, se reconoce la gravedad no solo del abuso,

${ }_{33}$ Ver Carta del Santo Padre Francisco al pueblo de Dios que peregrina en Chile, 4. En http://www.vatican.va/content/francesco/es/letters/2018/documents/papa-francesco_20180531_lettera-popolodidio-cile.html (visitado el 10 de enero de 2020). 
sino de su encubrimiento y, por otra, se complejiza la comprensión del abuso sexual, al considerarlo dentro del marco más amplio del abuso de conciencia y de poder ${ }^{34}$.

No se trataría, entonces, de tres tipos de vulneraciones, sino de que el abuso sexual, de conciencia y de poder están en el mismo plano comprensivo. Por eso se habla de cultura y no solo de actos. Lo que tradicionalmente se ha visto como un problema que se remite a la genitalidad, ahora se comprende desde la cultura y el ejercicio del poder. El abuso de poder es la utilización perversa de la asimetría de poder. Mientras que, dentro del contexto de la asimetría de poder, el abuso de la conciencia constituye la vulneración de la intimidad de la subjetividad humana, espacio interno que posibilita entrar en el movimiento de la existencia buscando sanamente sentido.

Hay una importante evolución gracias a los avances éticos, científicos y también en derechos humanos. Aquí es donde ubicamos las palabras del Pontífice del año 2018 estableciendo el abuso sexual, de poder y de conciencia en una cultura que la ha sostenido. Pero esta evolución requiere problematizar y actualizar el concepto mismo de abuso sexual, con todos los elementos que lo constituyen y la violencia que significa.

\section{HACIA UNA NUEVA DEFINICIÓN DE ABUSO SEXUAL}

Un concepto actualizado de abuso sexual requiere incorporar elementos que permitan comprender y generar estrategias de prevención, detección, intervención y acompañamiento a víctimas y comunidades donde ha ocurrido.

No se trata solo de declarar que el abuso sexual es una conducta indeseada, sino comprenderla en su integridad. La falta de definición y de fundamento ha llevado a confusiones importantes y ha dificultado la comunicación entre los agentes de intervención, ha impedido tomar decisiones claras ${ }^{35}$, siendo finalmente injusta, arbitraria o laxa, o asegurando impunidad más que protección y justicia.

${ }^{34}$ Ver http://www.vatican.va/content/francesco/es/letters/2018/documents/papafrancesco_20180820_lettera-popolo-didio.html (visitado el 10 de enero de 2020).

35 Sandra Baita y Paula Moreno. Abuso sexual infantil. Cuestiones relevantes para su tratamiento en la justicia. Montevideo: Unicef-Uruguay, 2015, 21. 
Tomaremos algunas de las definiciones que son normalmente utilizadas en el mundo profesional y académico de abuso sexual infantil e identificaremos algunos de sus elementos estructurales, y propondremos una nueva definición de abuso sexual más integral.

En primer lugar, una de las definiciones clásicas es la de la Organización Mundial de la Salud, en 1999:

«El involucramiento de un niño o niña en una actividad sexual en el que él o ella no puede comprender completamente, no está capacitado/a para dar su consentimiento informado, o para el que el niño o niña no está preparada por su etapa de desarrollo y no puede dar su consentimiento, o que viola las leyes o los tabúes sociales. El abuso sexual infantil se produce cuando esta actividad tiene lugar entre un niño/a y un adulto, o entre un niño/a y otro/a niño/a quien, por su edad o desarrollo, está en una relación de responsabilidad, confianza o poder; la actividad tiene por finalidad satisfacer las necesidades de otra persona $»^{36}$.

Por su parte, la Royal Comission australiana, en su reporte final del 2014, elabora una definición que toma estos elementos y los complementa.

"Cualquier acto que exponga a un niño, niña o adolescente, o lo involucre en procesos sexuales que van más allá de su comprensión o son contrarios a los estándares comunitarios aceptados. Comportamientos sexualmente abusivos incluyen los tocamientos de genitales, masturbación, sexo oral, penetración vaginal o anal por un pene, dedo o cualquier otro objeto, tocamiento de pechos, voyeurismo, exhibicionismo, y exposición del niño, niña o adolescente, o su involucramiento en pornografía. Esto incluye el proceso de preparación (grooming), que son las acciones tomadas deliberadamente con el propósito de generar y establecer conexión emocional con un niño, para disminuir sus barreras inhibitorias en vías de preparar la actividad sexual con él» ${ }^{37}$.

Esta definición, que fue elaborada luego de miles de entrevistas con personas que fueron víctimas de abuso sexual infantil en contextos institucionales y religiosos, contiene elementos que dan luz a la hora de comprender de manera más integral el abuso sexual. En efecto, no solo se refiere al acto vulneratorio mismo, sino también los actos preparatorios

${ }^{36}$ En Report of the consultation on Child Abuse Prevention. WHO, 1999, 15-16 (Visitado el 10 de enero de 2020. En https://apps.who.int/iris/handle/10665/65900)

37 Royal Commission, Final Report, 2:30. 
(grooming). Nos parece que a esta definición solo le falta complementar con las actividades posteriores a la vulneración genital, y que buscan el silenciamiento de la víctima y su entorno. De esta manera, el abuso sexual, más que un acto abusivo, es un proceso que comienza antes de la fase de abuso genital y termina después de ella.

Podemos encontrar, entonces, distintos elementos que caracterizan el abuso sexual infantil a partir de los cuales se establecerá una definición más amplia y comprensiva.

Antes de construir una definición de abuso conviene profundizar en algunos de los elementos clave para su comprensión. Esto permitirá, a su vez, elaborar estrategias que apunten al establecimiento de una cultura del cuidado.

\subsection{ASIMETRÍA DE PODER Y VULNERABILIDAD}

El neuropsiquiatra infantil chileno radicado en España, Jorge Barudy, escribe a raíz del abuso sexual infantil: «Es importante considerar la coerción y la asimetría de poder entre el adulto y el niño como factores estructurales fundamentales en la génesis del abuso sexual ${ }^{38}$. El mismo autor continúa: «Esta asimetría, basada en la diferencia de edad, la vulnerabilidad y la dependencia del niño, impide a este último participar en un verdadero intercambio y decidir libremente. Además, los niños tienen, en relación con el adulto, experiencias, grados de madurez y finalidades muy diferentes ${ }^{39}$.

La vulnerabilidad es un correlato estructural de la asimetría de poder. Hay poder donde hay vulnerabilidad, y la vulnerabilidad es una fragilidad expuesta ante un poder (que puede vulnerar).

La asimetría de poder está en la base de todo abuso, en especial del abuso de sexual. Para poder comprenderlo, es necesario cuestionar, aunque sea de manera sucinta, el concepto mismo de poder. Este concepto es esquivo. Para los efectos de esta investigación tomaremos prestada una definición amplia, desde el mundo de la psicología social, desarrollado

38 Jorge Barudy. El dolor invisible de la infancia. Una lectura ecosistémica del maltrato infantil. Buenos Aires: Paidós, 1998, 162.

39 Ibid. 
por el investigador norteamericano Dacher Keltner ${ }^{40}$. Trascendiendo las conceptualizaciones políticas y maquiavélicas (en sentido literal) de poder en cuanto pura dominación, coerción o manipulación, diremos que el poder consiste básicamente en la "posibilidad de alterar el estado de otra u otras personas». Y esta posibilidad se debe a la fragilidad inherente de todo ser humano, que le hace susceptible de ser alterado por otro.

Alterar en sí es una posibilidad sin contenido ético hasta que se realiza en una acción concreta. La alteración puede tener consecuencias integrativas en una persona o de fragmentación traumática. El acto de poder, como toda acción concreta, siempre tiene un posicionamiento ético. Sin entrar en la estructura moral de intenciones y acciones, que supera el propósito de esta investigación, solo diremos que el poder tiene consecuencias en el estado de las personas afectadas por estas mismas acciones. Los elementos presentes son la asimetría de poder y la vulnerabilidad consecuente de esta asimetría en la que se ejerce el poder. Mientras mayor es la asimetría - y por ende la vulnerabilidad- mayor es la posibilidad de alteración por un acto de poder. Y las consecuencias, también. En este sentido, podemos decir que mientras mayor es la asimetría de poder, mayor es la posibilidad de alteración, y asimismo, mayor es la responsabilidad de quien actúa.

La diferencia de edad es un parámetro cuantitativo objetivo para determinar la asimetría de poder. Sin embargo, esta asimetría no significa otra cosa que quien tiene más edad, ya sea por fuerza, experiencia, reputación u otros medios, es capaz de alterar de manera más efectiva el estado de la persona que tiene menos edad. Es importante dejar claro que la alteración, la influencia, el impacto que tiene una persona sobre otra por la asimetría de poder en que se encuentran no significa necesariamente dominación o abuso. El impacto de una acción en un contexto de asimetría de poder puede ser también, y usualmente ocurre, de cuidado, respeto, protección, integración psicológica o espiritual. La asimetría de poder es una realidad que se manifiesta éticamente dependiendo del contenido y consecuencias de la acción. Lo relevante para nuestra investigación es tener en cuenta la realidad de asimetría de poder como una condición de vulnerabilidad de una persona ante otra.

${ }^{40}$ Dacher Keltner. The Power Paradox. How we gain and loose influence. Nueva York: Penguin Random House, 2016. 
En los casos de abuso sexual en contextos clericales es importante asumir que la vulnerabilidad de quien se aproxima a un guía espiritual, confesor, superior o superiora de una congregación es directamente proporcional a la relación espiritual con la divinidad por parte de quien se expone. Se da, entonces, la mayor asimetría imaginable, porque es la asimetría de un ser humano abierta, expuesta ante lo divino. Esa asimetría debiera tener como correlato la responsabilidad más alta, puesto que quien está en esa relación responde por la imagen de Dios que tiene la persona que se expone. Una imagen de Dios que se despliega desde la intimidad más íntima, al igual que el abuso sexual, que se ejerce en la intimidad más íntima, en la sensibilidad abierta y expuesta. Quien se expone en una relación en la que lo divino está involucrado, se confía a sí mismo en la promesa divina de la fidelidad del cuidado. Quien abusa sexualmente en este contexto de asimetría está entrando en esa íntima vulnerabilidad y utilizándola, llevando al plano de la confusión traumática lo que debería ser ejercicio de respeto y cuidado infinitos. Infinito en el sentido en que no puede ser reducido a un contenido objetivo, sino que lo supera a modo de misterio ${ }^{41}$.

El abuso sexual en contextos eclesiales o espirituales constituye, así, una traición máxima, especialmente cuando se comete sin fuerza física, donde la confusión entre la ternura y anhelo espirituales y la pasión erótica es utilizada por quien se encuentra en posición de mayor poder, es decir, de cuidado o responsabilidad ante otro.

Los análisis y definiciones de abuso sexual, para recoger la real dimensión del daño, deberán hacerse cargo de los niveles de asimetría y vulnerabilidad en que el abuso normalmente se comete. La gran mayoría de los casos de abuso sexual son cometidos en contextos de intimidad y de parte de quien tiene a cargo el deber de cuidado ${ }^{42}$. Sin comprender la vulnerabilidad en que se encuentra una persona por la asimetría de intimidad en contextos de cuidado afectivo, no podrá ser comprendido tampoco el nivel de daño que ocurre con el abuso sexual, daño que puede llevar a la esquizofrenia, estrés postraumático, entre otros ${ }^{43}$.

${ }^{41}$ Ver Emmanuel Lévinas. Totalité et Infini. Essai sur l'extériorité. París: Martinus Nijhoff, 1971.

42 Cf. Finkelhor.

43 Ver Helen P. Hailes, Rongqin Yu, Andrea Danese, y Seena Fazel. "Long-term outcomes of childhood sexual abuse: an umbrella review". Lancet Psychiatry 6 (2019): 830-839. 


\subsection{El CONSENTIMIENTO}

En términos generales, el consentimiento es una manifestación libre, informada e integral de la voluntad de participar de una actividad. Y esto es fundamental en materia sexual ${ }^{44}$. En distintos países varían las maneras de tipificar el abuso sexual en mayores de edad cuando no hay fuerza, intimidación o trastorno mental ${ }^{45}$. Países como Canadá, por ejemplo, manejan una definición amplia de abuso sexual, e incluye cualquier acto sexual no deseado o consentido. El consentimiento lo define como «el acuerdo voluntario para participar en una actividad sexual ${ }^{46}$.

El consentimiento puede ser manipulado independientemente de la edad de la persona y de la fuerza física o intimidación, en determinadas circunstancias. Es importante problematizar el consentimiento en materia sexual, puesto que hay ordenamientos jurídicos o prejuicios judiciales que presumen consentimiento si no ha habido fuerza física, amenazas o incluso resistencia física. Los países por lo general están evolucionando en esta materia gracias a movimientos que defienden grupos vulnerables y vulnerados, y también al feminismo y el movimiento global \#MeToo. Más allá del consentimiento sexual genital, lo que algunos movimientos buscan es constituir una cultura del consentimiento, pensando que actualmente se vive una cultura que promueve la transgresión de límites ${ }^{47}$.

Entonces, más allá de las acciones de violencia, intimidación y aprovechamiento de situaciones de inconsciencia de una persona, hay otras estrategias y tácticas de anulación del consentimiento que hay que tener en cuenta. Aquí proponemos algunas que pueden servir a modo de marco comprensivo.

a) Confusión. Este término lo hemos tomado del psicoanalista húngaro Sandor Ferenzci y su última conferencia del año $1932^{48}$. Ferenzci

${ }_{44}$ David Archard. Sexual Consent. Boulder (Colo.): Westview Press, USA, 1998.

45 Código Penal de Chile, artículo 361.

${ }^{46}$ Código Penal 237.1, 1. Ver el artículo del sitio Women,'s Legal Education and Action Fund acerca del consentimiento sexual en materia penal: "The law of Consent in Sexual Assault" (https://www.leaf.ca/the-law-of-consent-in-sexual-assault/ visitado el 10 de enero 2020).

47 Ver, por ejemplo, el libro de Milena Popova. Sexual Consent. London: MIT Press Essential Knowledge, 2019.

${ }_{48}$ Sandor Ferenczi. "La confusión de lenguas entre adultos y el niño. El lenguaje de la ternura y el lenguaje de la pasión [sexual]". Traducción al inglés en The assault on Truth, Apéndice C. 
comprendió que, para muchos casos, la neurosis tenía su origen en seducciones erotizadas que los niños sufrían de parte de sus adultos más cercanos $^{49}$. La aproximación que para el niño, niña o para quien está en posición de menos poder significa ternura, cercanía, cuidado, confianza es utilizada y confundida por quien agrede a modo de relación erótica. Esta confusión no está en el plano racional sino afectivo y, por lo mismo, subjetivamente estructural. El abuso tiene su origen en la confusión que provoca el adulto en el niño y tiene como consecuencia también una confusión existencial en la víctima. Una confusión que podría terminar socavando la estructura misma de la subjetividad, conduciendo incluso a la esquizofrenia ${ }^{50}$, en el sentido de Gregory Bateson («doble vínculo»).

b) Relación de hechizo. Los autores Perrone y Nannini ${ }^{51}$ han llamado relación de hechizo a este proceso abusivo por la que quien comete el abuso fortalece su poder y debilita la capacidad de resistencia de la vícti$\mathrm{ma}^{52}$. Como lo sugiere la palabra, no se trata de fuerza física, sino manipulación cognitivo afectiva. Se lleva a cabo a través de «ritualizaciones» a través de las cuales logran modificar la conciencia y debilitar o eliminar el sentido crítico ${ }^{53}$. «La persona víctima de hechizo pierde su calidad de sujeto y se considera, cada vez más, un objeto» ${ }^{54}$. En su discurso se detecta de manera manifiesta un "pensamiento parasitado acompañado de falsas certidumbres» ${ }^{55}$.

Según estos autores, en la dinámica del hechizo y abuso sexual hay tres fases. La efracción, la captación y la programación. «El abuso sexual e incesto pueden ser asimilados a la estafa y al abuso de confianza, porque el abusador toma posesión de la víctima mediante argumentos falaces,

${ }^{49}$ Recomendamos: "The Strange Case of Ferenczi's last Paper", capítulo 5 en The Assault on Truth.

${ }^{50}$ La teoría del doble vínculo como génesis de la esquizofreia cobra relevancia en esta confusión. La relación entre doble vínculo e impacto subjetivo del abuso sexual infantil es una tarea a construir. Ver Gregory Bateson, Donald deAvila Jackson, Jay Haley, y John Weakland. "Toward a theory of schizophrenia". Behavioral Science 1 (1956): 251-264.

51 Reynaldo Perrone y Martine Nannini. Violencia y abusos sexuales en la familia. Una visión sistémica de las conductas sociales violentas. Buenos Aires: Paidós, 1997, capítulo 4: "Relación de hechizo", 157ss.

52 Cf. Ibid., 158.

53 Cf. Ibid., 159.

54 Ibid., 166.

55 Ibid. 
traicionando la confianza que esta depositó en él» ${ }^{56}$. En el caso del abuso sexual, cuando hay relación de «hechizo» la víctima tiene la sensación de dejar de tener posesión de su cuerpo y de su espíritu.

En la etapa de la efracción, el agresor logra entrar en el mundo interior de la víctima, gracias a la vulnerabilización, debilitación de sus defensas y sentido crítico.

En estos casos, el agresor

«[...] logra establecer una relación de confianza desactivando y desorientando a la víctima hasta que aquel ya se encuentra en su mundo, y despoja a la víctima de su posibilidad incluso de consentir o no. Franquea "las barreras de lo íntimo, desgarra la membrana que protege al sí mismo instalando los símbolos (fetiches) de su indefinible presencia” ${ }^{57}$.

Para esto ha tenido que captar su confianza, retener su atención y, poco a poco, privarlo de su libertad ${ }^{58}$.

En el caso del abuso sexual clerical, la efracción tiene un lugar natural, que es la enorme esperanza, generosidad y vulnerabilidad con que se aproxima un niño, niña, adolescente o cualquier persona en situación de necesidad o anhelo espiritual.

\subsection{UN PROCESO QUE SE PREPARA Y QUE SE PROLONGA}

Si bien el abuso sexual puede consistir en un acto abusivo, generalmente se trata de un proceso que comienza antes de la transgresión genital y termina después de ella. Comienza con las estrategias de preparación (grooming ${ }^{59}$ ), aproximación afectiva, generación de lazos de confianza con la víctima y su entorno, para bajar las barreras protectoras. Se trata de un proceso gradual en el que la confianza juega un importante rol. Son

\footnotetext{
56 Ibid., 167.

57 Ibid., 169.

58 Ibid.

59 Hemos tomado la explicación del proceso relacional abusivo y de grooming de Royal Commission. Final Report, 2:40: "We define grooming as behaviors that manipulate and control a child, their family and other support networks, or institutions with the intent of gaining access to the child, obtaining the child's compliance, maintaining the child's silence, and avoiding discovery of the sexual abuse. This definition takes a victim-centered approach and reflects what we were told during private sessions and public hearings, as well as being informed by research».
} 
actos muchas veces sutiles, calculados, que pueden hacer sentir bien a la víctima, confiada, protegida, comprendida, pero que tiene tienen como objetivo la vulneración de su intimidad sexual ${ }^{60}$.

Asimismo, es fundamental considerar como parte del proceso del abuso sexual en cuanto tal todas las acciones que tienen como finalidad silenciar a la víctima, confundirla, hacerla sentir culpable, avergonzada de lo que le ocurrió, sucia. Todas las barreras que, intencionadamente se establecen a la víctima y su entorno, deben ser consideradas como parte estructural del abuso sexual que sufrió. Esto tomando en cuenta tanto la intención de quien agrede, el rol que juega el silenciamiento en el abuso, como las consecuencias traumáticas, que tienden a ser tanto o más profundas que las provocadas por la etapa abusiva genital.

\subsection{El ASPecto GENitaL}

Evidentemente, en el abuso sexual hay un elemento genital, es decir, de vulneración de los límites sexuales genitales de una persona. Como veremos, no se reduce a ello, pero es importante nombrarlo. Diferentes investigaciones agrupan en tipos de abuso las diferentes vulneraciones, comprendiendo que hay ciertas tipologías que las hacen común. Aquí seguiremos las que han sido sistematizadas por la Royal Commission de Australia $^{61}, \mathrm{y}$, sin reducirse a una lista taxativa en las descripciones, son las siguientes:

a) Contacto abusivo sin penetración. Incluye tocamientos en los genitales o zonas erógenas. O hacer que la víctima realice estos tocamientos en zonas erógenas o genitales de quien agrede u otro para observarlo. También incluye el acoso, la masturbación o hacer a la víctima masturbar a otro/a.

b) Abuso sexual con penetración. La penetración puede ser con el pene, otra parte del cuerpo o un objeto.

c) Violación de la privacidad/intimidad. Aquí puede tener lugar cuando se obliga a un niño, niña o adolescente a desnudarse u observarlo en un lugar privado como un baño, habitación. Cualquier forma de voyerismo.

60 Cf. Ibid., 41.

61 Royal Commission. Final Report. 2. Nature and Causes, 32ss. 
d) Hacer que un niño presencie actos sexuales o material sexual. Este tipo de abuso sexual puede darse de manera presencial o por medios digitales. En persona consistiría en exhibir material pornográfico, actos sexuales o genitales, a modo de exhibicionismo. A través de medios tecnológicos puede consistir en mostrar imágenes, videos, sonidos, juegos. Como parte del proceso del abuso esta exhibición se usa para normalizar conductas sexualizadas y así preparar a la víctima.

e) Explotación sexual. Hay explotación sexual cuando un niño o niña es manipulado para participar en actividades sexual a cambio de alguna retribución o promesa de retribución, como afecto, atención, dinero, comida, protección, ropa, drogas, tabaco. Algunos lo llaman también prostitución infantil, pero preferimos no usar esta palabra porque puede entenderse como trabajo sexual que podría ser legitimado o consensuado. Aquí, por el contrario, hay manipulación o coacción, y hace imposible el consentimiento.

f) Producción, consumo, difusión e intercambio de material de explotación sexual infantil. Cualquier forma o material que represente sexualmente o explote a niños, lo que puede incluir fotografías, imágenes electrónicas, videos, dibujos o material escrito. La sola tenencia de este tipo de material, de manera voluntaria, constituye abuso sexual. Y este abuso puede continuar siéndolo incluso cuando el niño ya es adulto, al permanecer la imagen de él cuando era niño.

Una de las dificultades a la hora de comprender la profundidad del trauma en el abuso sexual infantil es que en sus definiciones, por lo general, se reduce al momento meramente genital, sin considerar que la sexualidad trasciende lo genital. La sexualidad es una categoría existencial del afectivo estar-en-el-mundo. Según Merleau-Ponty, siguiendo a Freud,

«[...] la libido [...] es el poder general que tiene el sujeto psicofísico para adherir a diferentes medios, para fijarse por diferentes experiencias, de adquirir estructuras de conducta. Es lo que hace que el ser humano tenga una historia. Si la historia sexual de un ser humano constituye la clave de su vida, es porque en la sexualidad del hombre se proyecta su manera de ser respecto del mundo, es decir, respecto del tiempo y respecto de los otros hombres» ${ }^{62}$.

${ }^{62}$ Maurice Merleau-Ponty. "Le corps comme être sexué". En Phénoménologie de la Perception, Gallimard, París, 1945, 196 (traducción nuestra). 
El cuerpo, sus límites, la sexualidad son fuerza de la proyección afectiva y, por lo tanto, orientadora del ser humano en el mundo, entre los demás seres humanos, respecto de sí mismo y del infinito. Solo así se comprende la profundidad del impacto traumático del abuso sexual. Si se tratara de un problema genital, solo se manifestaría en lo genital. Sin embargo, como se ha ido demostrando, las consecuencias a largo plazo del abuso sexual infantil tienen impacto en la estructura misma del sujeto que ha sido víctima. Así, un enorme metaanálisis ${ }^{63}$ publicado en octubre de 2019 demostró la relación a largo plazo del abuso sexual infantil en los planos psicosociales, físicos y psiquiátricos, siendo la esquizofrenia, el estrés postraumático y el abuso de sustancias las consecuencias más fidedignas de la vulneración sexual en la infancia. En ese mismo estudio los autores dicen no saber exactamente cómo ocurre esto, pero las consecuencias pueden llegar a ser de ese nivel de daño estructural. Esto solo tendría sentido por la profunda conexión entre la sexualidad y el estar-en-el-mundo, afectivamente en búsqueda de sentido y de orientación existenciales, donde el cuerpo no es máquina ni res extensa, ni objeto, sino eje de orientación del sentido ${ }^{64}$.

Sin comprender que la existencia humana se mueve y se orienta en el mundo de manera afectiva, es decir, sexuada ${ }^{65}$, es muy difícil compren-

${ }^{63}$ Hailes, Yu, Danese y Fazel, 830-833.

${ }^{64}$ El cuerpo como centro de orientación lo establece Edmund Husserl en Ideas II, parágrafo 41. Lo retoma en fenomenología de manera especial Jan Patočka, en "Leçons sur la corporalité" publicado en Papiers phénoménologiques. Grenoble: Jérôme Millon, 1995. Lo que es interesante es que esta idea de corporalidad, de ser humano encarnado en un cuerpo ha estado en conflicto y diálogo tanto desde el dualismo platónico, cartesiano y cristiano. Justamente en la visión de abuso sexual es donde el concepto se materializa de manera más clara, no a modo sujeto integral, encarnado, sino disociado, dualizado.

${ }_{65} \mathrm{El}$ análisis fenomenológico de Maurice Merleau-Ponty en su Phénoménologie de la Perception. París: Gallimard, 1945, en el capítulo V: "Le corps comme être sexué", 181-202, entrega una visión muy aguda de la estructura sexuada del ser humano y que trasciende el momento genital. Encontramos en estos análisis fenomenológicos estructurales las razones de la profundidad del trauma por abuso sexual. En este texto Merleau-Ponty dialoga con el psicoanálisis y reconoce la trascendencia de lo afectivo en la relación con el mundo y la propia historia. Nos parece que hace falta un análisis más profundo del trauma sexual desde esta visión, que sea capaz de ir más allá del trauma genital relacional y pueda verlo como un trauma afectivo-existencial. En efecto, hay una fuente común en la estructura afectiva con la capacidad para confiar y la existencia sexuada, de modo tal que una vulneración sexual agrede no 
der la gravedad del abuso sexual. En este sentido, proponemos tomar en cuenta, a la hora de analizar el abuso sexual infantil, todas las circunstancias psicotraumáticas que rodean el abuso, e incluirlas como parte del abuso mismo. El aislamiento del abuso a su momento genital, como veremos, puede constituir una vulneración en sí mismo.

\subsection{Definición InTEgral}

Llegado a este punto, nos encontramos en condiciones de ensayar una nueva definición de abuso sexual, que no se agota en ella misma, sino que abarca los elementos que venimos describiendo. Esta definición, si bien apunta al abuso sexual cometido a menores de edad, busca no reducirse a la edad, sino a las asimetrías de poder posibles que hacen que una interacción sea abusiva y vulneratoria. En base a esta definición proponemos, entonces, comprender el abuso sexual en toda circunstancia en la que haya asimetría de poder y aprovechamiento de esta asimetría para imponer una voluntad, una sexualidad sobre otra persona.

El abuso sexual infantil es todo acto y proceso de actos, en que se expone o involucra a un niño, niña o adolescente en cualquier actividad sexualizada, utilizando la asimetría que da la autoridad, la confianza, la dependencia (afectiva, social o económica), el poder, la fuerza, el miedo, la cultura, la capacidad comprensiva, la necesidad u otras vulnerabilidades, manipulando, confundiendo, eliminando o viciando el consentimiento. Estos actos pueden incluir, aunque no se reducen a esta lista: tocamientos genitales, penetración oral, vaginal o anal, con pene, dedos u otros objetos; tocamiento de otras partes erógenas del cuerpo; incitación a tocar a otros, masturbación, voyerismo, exposición a situaciones sexuales, pornografía, abusos, violaciones. Tanto las acciones, tácticas y estrategias de preparación de estos actos (grooming presencial u online), como las de silenciamiento y desprestigio de la víctima y su entorno, constituyen también parte del proceso del abuso sexual.

solo lo genital, sino la estructura afectiva, sexual y, por lo tanto, también la capacidad para confiar, es decir, para orientarse afectivamente en el mundo. Hemos realizado las primeras aproximaciones fenomenológicas a este problema en Confianza lúcida. Santiago de Chile: Uqbar, 2012, pero es necesaria una profundización. 


\section{CONCLUSIÓN: NOTAS HACIA UNA CULTURA DEL CUIDADO}

En la carta de agosto de 2018, el papa Francisco agrega un concepto que hace de contrapunto a la cultura del abuso y el encubrimiento. Es la cultura del cuidado. Es importante detenerse en esta cultura del cuidado y preguntarse cómo se hace práctica, y no solo en el contexto de la Iglesia católica, sino en todo contexto en que la asimetría expone la vulnerabilidad de unos ante el poder de otros. Esta vulnerabilidad expuesta reclama un compromiso de quien tiene más poder.

La hermenéutica de la confianza, propuesta por la psicoanalista Dona Orange, en su libro The Suffering Stranger ${ }^{66}$, como alternativa opuesta a la hermenéutica de la sospecha, de la culpa, de la distancia y falta de reconocimiento constituye una práxis ética a construir en relaciones donde la vulnerabilidad está en juego, como, por ejemplo, en una relación terapéutica, comparable también a una relación en contextos eclesiales o espirituales.

Las palabras del terapeuta ante un paciente son como las de un adulto ante un niño, establece Orange ${ }^{67}$. Ese es el nivel de asimetría que hay que tomar en cuenta para el terapeuta, y aún más para un guía espiritual, superior o superiora o confesor.

El abuso, cometido en contextos así de asimétricos, se apalancan en la confusión de la vulnerabilidad de quien busca refugio de la trascendencia. Cuando no es la fuerza física sino la ambigüedad, la manipulación, el engaño de la promesa de cuidado en abuso mismo, entonces el daño llega hasta la profundidad misma del ser de quien es víctima. De ahí las constantes consecuencias en la estructura misma de su personalidad. Por eso el cuidado debe ser promesa irrestricta ante la confianza de quien se aproxima buscando refugio espiritual. En efecto, en el concepto mismo de confianza hay una promesa de cuidado ${ }^{68}$.

${ }^{66}$ Donna Orange. The Suffering Stranger: Hermeneutics for Everyday Clinical Practice. Nueva York: Taylor \& Francis e-Library, 2011.

67 «Just as adults are giants to children, the words of therapists and analysts may carry more weight than we realize, and the equilibrium of the dialogic process will need restoration".

68 «Detrás de la confianza, y casi sosteniéndola, hay una promesa, aunque no se la declare ni se la explicite, del que recibe la confianza. El origen de la palabra confianza (fides) tiene que ver con una petición de no dañar. El más frágil pide fides al más poderoso para que lo proteja, para que no lo dañe, no abuse de él, es decir, se confía en él y le pide poder confiar. Confiar, confiarse o confiar algo a alguien significa tener la esperanza de que ese alguien no hará daño sino que cuidará, respetará, 


\section{BIBLIOGRAFÍA}

Agamben, Giorgio. Infancia e historia. La destrucción de la experiencia y el origen de la historia. Buenos Aires: Ed. Adriana Hidalgo, 2003.

Ambroise-Rendu, Anne-Claude. Histoire de la pédophilie XIXe-XXIe siècles. París: Fayard, 2014.

Archard, David. Sexual Consent. Boulder (Colo.): Westview Press, USA, 1998.

Ariès, Philippe. L'Enfant et la vie familiale sous l'ancien régime. París: Librairie Plon, 1960.

Baita, Sandra, y Paula Moreno. Abuso sexual infantil, cuestiones relevantes para su tratamiento. Montevideo: Unicef, 2015.

Barudy, Jorge. El dolor invisible de la infancia. Una lectura ecosistémica del maltrato infantil. Buenos Aires: Paidós, 1998.

Bateson, Gregory, Donald deAvila Jackson, Jay Haley, y John Weakland. "Toward a theory of schizophrenia". Behavioral Science 1 (1956): 251-264. DOI: https://doi.org/10.1002/bs.3830010402

Benjamin, Jesssica. Beyond Doer and Done To. Recognition Theory, Intersubjectivity and the Third. Nueva York: Routledge, 2018.

Bourdieu, Pierre y Claude Passeron. "Fundamentos de una teoría de la violencia simbólica”. En La Reproducción. Elementos para una teoría del sistema de enseñanza, 39-105. Coyoacán (México): Ediciones Distribuciones Fontamara, S. A., 1995 (traducción de la versión francesa. París: Les Éditions de Minuit, 1970).

Dale, Kathryn A., y Judith L. Alpert. "Hiding Behind the Cloth: Child Sexual Abuse and the Catholic Church". Journal of child sexual abuse 16 (2007): 59-74. DOI: https://doi.org/10.1300/j070v16n03_04

DeMause, Lloyd, ed. The History of Childhood. Nueva York: Rowman \& Littlefield, 1974.

Ferenczi, Sándor. Obras Completas. Vol. 4, Psicoanálisis. Madrid: Espasa-Calpe, 1984.

Finkelhor, David, R. Ormrod, H. Turner, y S. L. Hamby. "The Victimization of Children and Youth: A Comprehensive, National Survey". Child Maltreatment 10, n. ${ }^{\circ} 1$ (February 2005): 5-25. DOI: https://doi.org/10.1300/ j070v16n03_04

protegerá lo confiado. Puede hacer daño, puede traicionar la confianza que ha sido depositada en él, pero el que confía, espera que no lo hará. ¿Por qué? Porque hay algo en la confianza que crea una promesa de protección, promesa que por su puesto que puede ser quebrada». (José A. Murillo. Confianza lúcida, 87). 
Formicola, Jo Renee. Clerical Sexual Abuse: How the Crisis Changed US Catholic. Nueva York: Palgrave Macmillan, 2014.

Francisco. "Carta del Santo Padre Francisco al pueblo de Dios que peregrina en Chile". Fecha de la última modificación: 31 de mayo de 2018. Fecha de la consulta: 10 de enero de 2020. http://www.vatican.va/content/francesco/es/letters/2018/documents/papa-francesco_20180531_lettera-popolodidio-cile.html

Frawley-O'Dea, Mary Gail, y Virginia Goldner. Predatory Priests, Silenced Victims: The Sexual Abuse Crisis and the Catholic Church. Nueva York: Lawrence Erlbaum Associates, 2007.

German Bishops Conference. "Sexual abuse of minors by catholic priests, deacons and male members of orders in the domain of the German Bishops' Conference". Fecha de la última modificación: 25 de septiembre de 2018. Fecha de la consulta: 7 de enero de 2020. https://dbk.de/

Gibney, Alex, dir. Mea Maxima Culpa. El silencio en la casa de Dios. HBI, 2012. Hailes, Helen P., Rongqin Yu, Andrea Danese, y Seena Fazel. "Long-term outcomes of childhood sexual abuse: an umbrella review". Lancet Psychiatry 6 (2019): 830-839. DOI: https://doi.org/10.1016/S2215-0366(19)30286-X Heifetz, Ronald. Leadership Without Easy Answers. London: The Belknap Press of Hardvard University Press, 1998.

Husserl, Edmund. Ideas pertaining to a pure phenomenology and to a Phenomenological philosophy, II [1950]. Version en inglés de Richard Rojcewicz y Andre Schuwer, Dordrecht: Kluwer Academic Publishers, 1989.

Jackson, Louis A. Child sexual abuse in Victorian England. Nueva York: Routledge, 2000.

John Jay College of Criminal Justice. "The nature and scope of sexual abuse of minors by catholic priests and deacons in the united states". Fecha de la última modificación: 19 de julio de 20011. Fecha de la consulta: 7 de enero de 2020. http://www.usccb.org/

Le Breton, David. Anthropologie du corps et modernité. París: PUF, 1990.

Le Breton, David. Anthropologie de la douleur. París: Métailié, 1995

Lévinas, Emmanuel. Totalité et Infini. Essai sur l'extériorité. París: Martinus Nijhoff, 1971.

McCarty, Tom, dir. Spotlight. Anonymous Content, Participant Media, First Look Media, Rocklin/Faust, 2015.

Merleau-Ponty, Maurice. "Le corps comme être sexué". En Phénoménologie de la Perception, 181-202. París: Gallimard, 1945.

Moussaieff, Jeffrey. The Assault on Truth. Freud's Suprression of the sexuction Theory. San Francisco: Untreed Reads, 2012. (Versión E-Pub). 
Murillo, José A. Confianza lúcida. Santiago: Uqbar, 2012.

Nijenhuis, Ellert. The Trinity of Trauma: Ignorance, Fragility, and Control. Gotinga: Vandenhoeck \& Ruprecht, 2015.

Orange, Donna. The Suffering Stranger. Hermeneutics for Everyday Clinical Practice. Nueva York: e-Library: Taylor \& Francis, 2011.

Ozon, François, dir. Grâce à Dieu. Mandarin Films y Scope Pictures, 2019. Patočka, Jan. "Leçons sur la corporéité". En Papiers phénoménologiques, versión francesa de Erika Abrams. Grenoble: Jérôme Millon, 1995.

Perrone, Reynaldo, y Martine Nannini. Violencia y abusos sexuales en la familia. Una visión sistémica de las conductas sociales violentas. Buenos Aires: Paidós, 1997.

Pinker, Steven. Los ángeles que llevamos dentro. El declive de la violencia y sus implicaciones. Barcelona: Paidós, 2011.

Popova, Milena. Sexual Consent. London: The MIT Press Essential Knowledge series, 2019.

Ricoeur, Paul. Le Juste. París: Esprit, 1995.

Royal Commission de Australia. Royal Commission into Institutional Responses to Child Sexual Abuse, Final Report. Fecha de la última modificación: 15 de diciembre de 2017. Fecha de la consulta: 7 de enero de 2020. https://www.childabuseroyalcommission.gov.au/

Sáez Martínez, Gil José. "Aproximación histórica a los abusos sexuales a menores". Eguzkilore 29 (2015): 137-170.

Solé, Albert, dir. Examen de Conciencia. Netflix, España, 2019.

Szczaranski, Federico. "Sobre la evolución del bien jurídico penal: un intento de saltar más allá de la propia sombra". Política Criminal 7, n. ${ }^{\circ}$ 14 (2012): 378-453.

Tapsell, Kieran. Potiphar's Wife. The Vatican's Secret and Child Sexual Abuse. Adelaide: ATF Press, 2014.

Toulalan Sarah, y Kate Fisher, eds. The Routledge History of Sex and the Body, 1500 to present. Nueva York: Routledge, 2013.

Walker, Garthine. "Sexual violence and rape in Europe, 1500-1750". En The Routledge History of Sex and the Body, 1500 to present, 429-444. Nueva York: Routledge, 2013.

Women's Legal Education and Action Found. "The Law of Consent in Sexual Assault". Fecha de la consulta: 10 de enero de 2020. https:/www.leaf.ca/

World Health Organization. Report of the Consultation on Child Abuse Prevention. Geneva: World Health Organization, 1999. 